\title{
The National School Meal Program in India: A Literature Review
}

\author{
Maki Nakao*1 and Yukie Tsuno*2 \\ ${ }^{* 1}$ Health Nutrition Support Center \\ ${ }^{* 2}$ Izumi City General Hospital
}

doi:10.5264/eiyogakuzashi.76.S105

\begin{abstract}
Objective: To describe the Indian school meal program (Mid-Day Meal: MDM) with the aim of improving the nutritional status of children.

Method: This study investigated the Indian central government's reports and articles about the school meal program.

Results: In India, the MDM has been institutionalized, along with compulsory education. In 2015 2016, MDM coverage was 81\%, with a high proportion of MDM working days. However, the school attendance rate was low, with many absent children. Despite established nutritional standards for school meals and hygiene management guidelines, there were no data on school compliance rates. To evaluate processes, each school reported to the central government, as part of a national system of monitoring system operational situations (e.g., coverage). The expected improvement in children's nutritional status after the introduction of the MDM has never been confirmed because no national health survey has been carried out to evaluate outcomes. By introducing the MDM and promoting compulsory education, the central government has triggered a rise in school enrollment rates. A plan-do-check-act (PDCA) system is in place, with a Steering-cum-Monitoring Committee assuming a key role in this system.

Conclusions: When the MDM was institutionalized in India, along with compulsory education, it represented the world's largest school meal program. The Japanese experience of introducing a children's national health surveillance system could be useful in evaluating the success of the MDM program in improving children's nutrition.
\end{abstract}

Jpn. J. Nutr. Diet., Vol.76 Supplement 1 S105-S114（2018）

Key words: school meal program, coverage, nutrition management, program evaluation, India

\section{Introduction}

A school meal program can play an important role in increasing school attendance rates, providing an educational and social safety net, ensuring healthy child growth, and encouraging local agricultural production in lowincome countries ${ }^{1,2)}$. Although previous reviews of school meal programs in low-income countries have evaluated program sustainability, they have focused on costs and budgets $^{1,2)}$. The nutritional guidelines and menus adopted by school meal programs have been studied and evaluated $^{3)}$. However, few studies have assessed school meal programs in low-income countries to discover whether (or to what extent) they have improved the nutritional status and healthy growth of children.

Although previous studies have presented an overview of the Indian school meals program, detailing its background, objectives, and components ${ }^{4)}$, few have assessed its current status or the challenges associated with improving the nutritional status and healthy growth of children. The present study fills this gap by reviewing the program, with the aim of improving school meals, not only in India, but also in other countries. To achieve this, we have used three indicators: coverage, school meal quality, and evaluation and feedback, focusing on the following elements:

1. The coverage provided by school meals (the number of students served)

2. The quality of school meals (e.g., nutritional management, hygiene management, and nutrition education)

3. Evaluation and the plan-do-check-act (PDCA) cycle (in particular, whether assessment outcomes related to children's health or growth have been obtained) 


\section{Method}

The present study has focused on six key aspects of nutritional programs: the health and nutritional status of schoolchildren; school meal program objectives and the history of national policies, laws, and guidelines; implementation systems; coverage: the number of children served; the quality of school meals; and evaluation and feedback systems. Three areas: the quality of nutritional management; hygiene management; and nutritional education have been used as criteria to determine the quality of school meals. As these three areas are advanced fields in Japan, exploring Indian school meals from a Japanese perspective can highlight problems in the Indian program. The Indian process and outcomes have been evaluated to determine whether the school lunch program is being managed well.

Research materials have included relevant literature, including government reports, the school meal program website, and articles located through the Medline database.

\section{Results}

\section{Basic information and the nutritional status of Indian children}

In 2015, India's population numbered 1.309 billion; children between the ages of 0 and 14 made up $28.7 \%{ }^{5)}$ of the population. In primary schools, the gross enrollment ratio (number of pupils of any age enrolled in primary education, as a percentage of the total official school-age population) was $107.9 \%$; in 2014, the net enrollment ratio (number of pupils of official primary school age enrolled in primary education as a percentage of the total number of children in the official school-age population) was $90 \%$. In 2010, the agricultural employment ratio was $51.9 \%$. As of 2015 , India was regarded as a lower-middle-income country with a per capita GDP of US $\$ 1,593.30$.

In India, children under five have a stunted rate of growth (height for age) of $38.4 \%$ and an underweight rate (weight for age) of $35.7 \%{ }^{6}$. Data from local investigations (Table 1) have shown the prevalence of undernutrition in children (weight for age) to be $63 \%$ for children aged 6 9, $78 \%$ for children aged 10 13, and $66 \%$ for children aged $14 \sim 17^{7)}$
Table 1 Distribution (\%) of school-age children and adolescents in some regions of India, according to nutritional status (weight for age)

\begin{tabular}{|c|c|c|c|c|c|}
\hline \multirow{2}{*}{$\begin{array}{l}\text { Age group } \\
\text { (years) }\end{array}$} & \multirow{2}{*}{$n$} & \multicolumn{4}{|c|}{ Nutritional status* } \\
\hline & & Normal $^{\dagger}$ & Mild ${ }^{\ddagger}$ & Moderate ${ }^{\S}$ & Severe \\
\hline $6 \sim 9$ & 5,453 & 5.4 & 31.9 & 54.0 & 8.6 \\
\hline 10 13 & 4,526 & 3.9 & 18.2 & 47.8 & 30.1 \\
\hline $14 \sim 17$ & 2,420 & 4.5 & 29.5 & 47.1 & 18.9 \\
\hline
\end{tabular}

* National Center for Health Statistics (NCHS) Standards

$\dagger>90 \%$ weight for age (NCHS)

‡ 75 89.99\% weight for age (NCHS)

\& $60 \sim 74.99 \%$ weight for age (NCHS)

$\|<60 \%$ weight for age (NCHS)

Source: National Nutrition Monitoring Bureau (2002) ${ }^{7)}$

Table 2 Energy requirements for different groups in India

\begin{tabular}{lcccc}
\hline \multicolumn{1}{c}{ Group } & $\begin{array}{c}\text { Mean weight } \\
\mathrm{NNMB}^{\dagger} \\
(\mathrm{kg})\end{array}$ & $\begin{array}{c}\text { (a) } \\
\text { Requirement } \\
\text { for mean } \\
\text { weight } \\
\text { (kcal) }\end{array}$ & $\begin{array}{c}\text { (b) Actual } \\
\text { intake } \\
\text { (kcal) }\end{array}$ & $\begin{array}{c}\text { Gap } \\
\text { (a) } \sim(b) \\
\text { (kcal) }\end{array}$ \\
\hline Adult man & 51 & 2,346 & 2,000 & -346 \\
Adult & 46 & 1,886 & 1,738 & -148 \\
woman & - & 2,336 & 1,726 & -510 \\
Pregnant & - & 2,386 & 1,878 & -518 \\
Lactating & - & 840 & 714 & -126 \\
1 3 y & 10.5 & 1,095 & 978 & -117 \\
$4 \sim 6$ y & 14.6 & 1,379 & 1,230 & -149 \\
$7 \sim 9$ y & 19.7 & & & \\
Boys & & 1,729 & 1,473 & -256 \\
$10 \sim 12$ y & 26.6 & 2,208 & 1,645 & -563 \\
$13 \sim 15$ y & 36.8 & 2,514 & 1,913 & -601 \\
$16 \sim 17$ y & 45.7 & & & \\
Girls & & 1,469 & 1,384 & -85 \\
$10 \sim 12$ y & 26.7 & 2,030 & 1,566 & -464 \\
$13 \sim 15$ y & 36.9 & 2,130 & 1,630 & -500 \\
$16 \sim 17$ y & 42.6 & & & \\
\hline
\end{tabular}

${ }^{\dagger}$ Mean weights derived from the results of a National Nutrition Monitoring Bureau study.

Source: Working Group Report on Elementary Education and Literacy in the 12th Five Year Plan (2012 2017) ${ }^{8}$.

The standard energy requirements for each age group are based on an average weight; Indian children's actual intake and the gap between the required nutrition and actual intake are shown in Table 2 . The gap between the requirements and actual intake was widest among adolescents $^{8)}$. These results show that India urgently needs to improve the nutritional status of children. 


\section{Implementation of the school lunch program}

The Indian school meals program is called the Mid-Day Meal (MDM) scheme. Launched in 1995, it became mandatory in 2001, with the following objectives: "to solve hunger in schools by serving a hot cooked meal, to improve the nutritional status of children, and to encourage poor children belonging to disadvantaged sections to attend school more regularly and to help them concentrate on classroom activities, thereby increasing the enrollment, retention and attendance rates"9).

Table $3^{9 \sim 25)}$ shows the MDM's history. To enforce the program, roles exist all levels: country, state, district, block, Gram Panchayat (local self-government organization of the Panchayat raj system at the village or smalltown level), local government, and school. Grains (rice or wheat) are procured by the Food Corporation India and donated gratis by the central government. The National Steering-cum-Monitoring Committee (SMC), which monitors the program, assesses its impact, coordinates departments and agencies, and provides policy advice to central and state governments. States and Union Territories (UTs) are required to establish SMCs at the state, district, and block levels to monitor program implementation. All state governments and UTs must authorize one department to assume overall responsibility for program implementation. In other words, nodal departments must establish implementation cells to monitor program implementation at the school level. The Gram Panchayat or municipality may assign program supervision at the school level to the Village Education Committee (VEC), School Management and Development Committee (SMDC), or Parent Teacher Association (PTA); these bodies are then accountable to the Gram Panchayat or municipality. Responsibility for cooking and supplying the meals is entrusted to local women's self-help groups, local youth clubs affiliated with the Nehru Yuvak Kendras, voluntary organizations, or personnel engaged by the VEC, SMDC, PTA, Gram Panchayat, or individual municipalities. In urban areas, where a group of schools may share a centralized kitchen, hot cooked meals are transported to schools ${ }^{9)}$. In 2016, the cost of food preparation came to Rs. 4.13 (primary) and Rs. 6.18 (upper primary) per child per day. Central and state governments share this cost and the central government covers the costs of all UTs. Parents do not contribute. During the 2015 2016 school year, lunch operating costs totaled Rs. 915.155 million ${ }^{26)}$; school meals accounted for $0.51 \%{ }^{27)}$ of the nation's total expenditure, a drop from 2012 2013, when school meals made up $0.77 \%$ of the whole.

\section{MDM coverage}

The MDM program targets children in the primary (Classes I-V: 5 9 years old) and upper primary age groups (Classes VI-VIII: 10 12 years old), providing meals to government-run, locally supported, and government-aided schools, as well as to schools in the EGS (Education Guarantee Scheme: alternative schools in underserved locations without a formal school within a radius of 1 kilometer and at least 15 25 children ages 6 14 not attending school), AIE (Alternative and Innovative Education: alternative, temporary schools that accommodate child workers, immigrants, and slum and street children), and to Madrasas and Maqtabs (Islamic primary and upper primary schools). The total number of target schools and students comes to approximately 1.192 million and 104.6 million, respectively ${ }^{8)}$. In 2010 2011, there were approximately 1.196 million primary and upper primary schools and 197.4 million school children in Classes I-VIII ${ }^{28)}$, making India's school feeding program the world's largest. Importantly, only $68.8 \%{ }^{6)}$ of girls aged 6 or older have ever attended school; $31.2 \%$ of girls have never been to school. In fact, even if they are registered for a school place, many children do not attend school. Estimates (2011) place the population of children between 6 and 13 at about 208.2 million $^{29)}$; this figure shows that roughly 10.89 million children have never been to school.

During the 2015 2016 school year, state and UT reports indicated that MDM coverage was $81 \%^{30)}$; this figure was calculated by totaling the average coverage in each state and then averaging the entire nation's coverage. The 2006 MDM Guidelines required the MDM program to be implemented for more than 200 days per year; however, the number of MDM working days differs from state to state; as a result, coverage of the denominators for each stage is not unified. In the present study, we have used state reports to calculate the average number of working days $^{30)}$. Our findings show that, in 2015 2016, the percentage of working days was high, at $94 \%$.

\section{Quality of MDM}

Table 4 presents the MDM food standards or norms. The MDM standard/recommended dietary allowance 


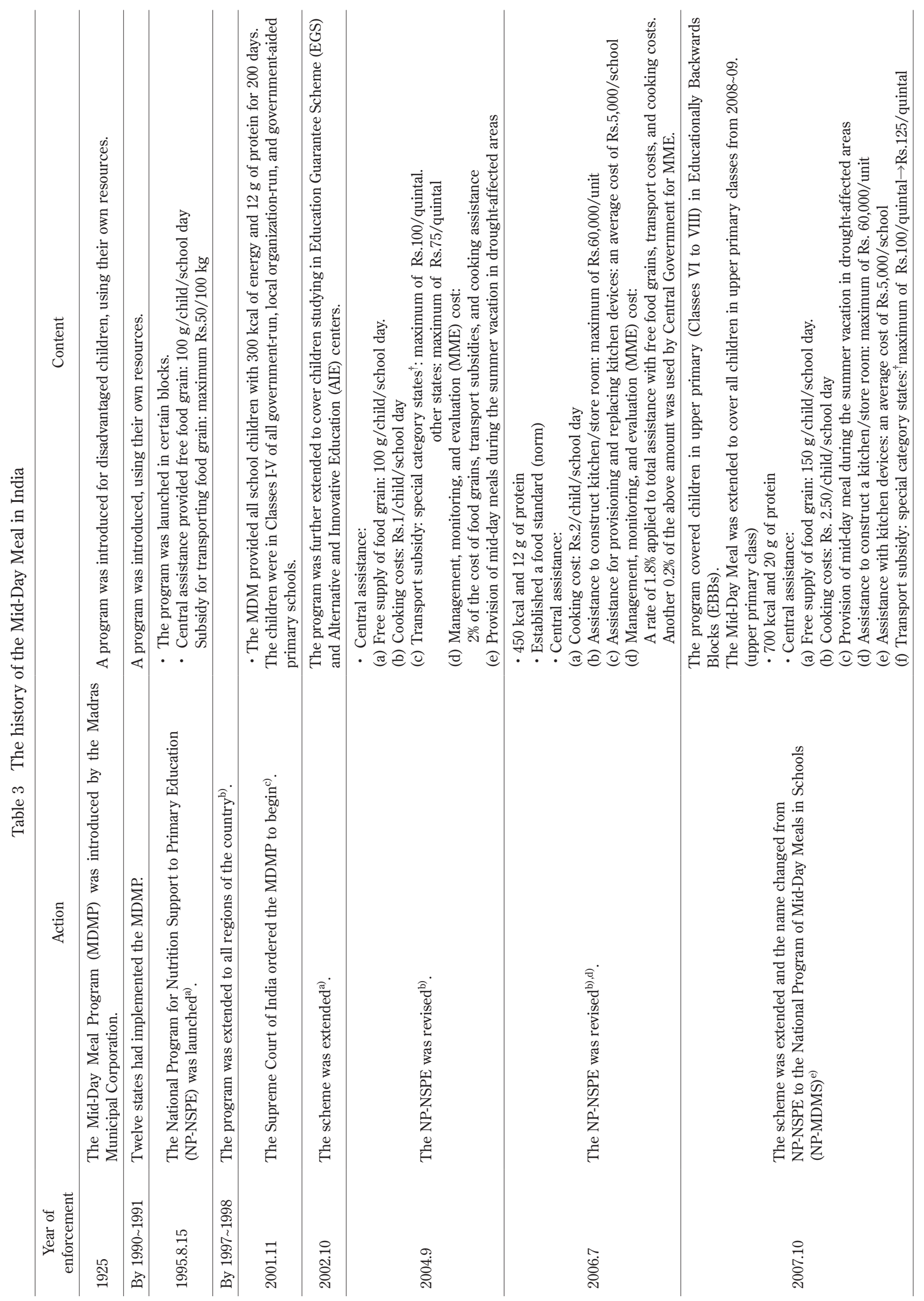




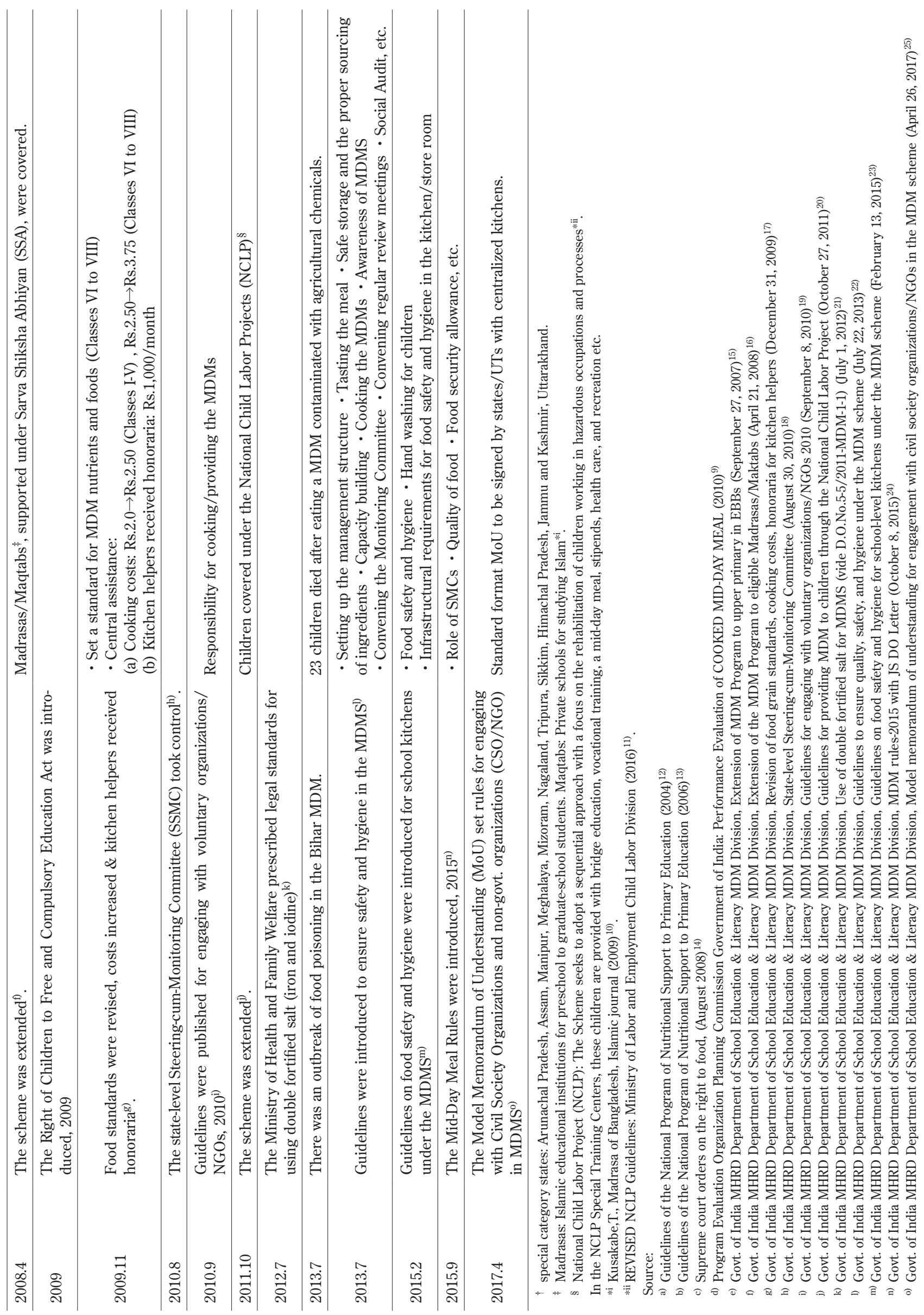


Table 4 The Mid-Day Meal food standards in India

\begin{tabular}{|c|c|c|c|}
\hline & & $\begin{array}{l}2006^{\dagger} \text { Primary } \\
(\text { Classes I V) }\end{array}$ & $\begin{array}{c}2009^{\ddagger} \text { Upper Primary } \\
\text { (Classes VI VIII) }\end{array}$ \\
\hline \multicolumn{2}{|c|}{ Energy (kcal) } & 450 & 700 \\
\hline \multicolumn{2}{|c|}{ Protein $(g)$} & minimum 12 & minimum 20 \\
\hline \multicolumn{2}{|c|}{ Micronutrients } & \multicolumn{2}{|c|}{$\begin{array}{l}\text { Adequate quantities of micronutrients } \\
\text { including iron, folic acid, vitamin A, etc. }\end{array}$} \\
\hline \multirow[t]{5}{*}{ Items $(\mathrm{g})$} & Food grains & 100 & 150 \\
\hline & Pulses & 20 & 30 \\
\hline & $\begin{array}{l}\text { Vegetables } \\
\text { (including leafy vegetables) }\end{array}$ & 50 & 75 \\
\hline & Oil \& fat & 5 & 7.5 \\
\hline & Salt \& condiments & As per need & As per need \\
\hline
\end{tabular}

Source:

$\dagger$ Guidelines of the National Program of Nutritional Support to Primary Education (2006) ${ }^{13)}$

‡ Govt. of lndia MHRD, Department of School Education \& Literacy MDM Division: Revision of food standards, cooking costs, and honoraria for kitchen helpers under the National Program for Mid-Day Meals in Schools ${ }^{17)}$

Table 5 Recommended dietary allowances (RDA) and balanced diets for infants, children, and adolescents

\begin{tabular}{cccccccc}
\hline & \multicolumn{2}{c}{ RDA2010 } & \multicolumn{3}{c}{ Balanced diets for infants, children, and adolescents } \\
number of portions (g)
\end{tabular}

Based on the Nutrient Requirements and Recommended Dietary Allowances for Indians (2009) ${ }^{31)}$, Dietary Guidelines for Indians (2011) ${ }^{32}$

(RDA) in India ${ }^{31)}$ (Table 5) has been calculated to build Table 6. Although the amount of energy provided to children was generally less than $30 \%$ of their recommended daily allowance, protein mass came to more than $30 \%$. Next, we calculated the MDM standard/recommended amount of each food item (Table 5$)^{32}$, as shown in Table 6. Although the MDM standards provide one-third of meals in the form of food grains and pulses, as required, it is likely that lower-class children receive a higher proportion of food grains. For these children, the lunches include a very small amount of oil, fat, and vegetables.

An assessment of the food provided in the region surrounding the national capital, Delhi, revealed that $90 \%$ of lunches did not meet $\mathrm{MDM}^{33,34)}$ standards. In India, schools are not required to hire dieticians. State governments, local governments, school teachers, NGOs, and other bodies are therefore obliged to create their own MDM menu plans ${ }^{13)}$. The MDM scheme thus lacks dietetic experts to take responsibility for administering schools lunches nationwide.

After a food poisoning case caused a child's death in 2013, hygiene management was emphasized. In 2015, the Guidelines on Food Safety and Hygiene for School Level Kitchens under MDM Scheme ${ }^{23)}$ was published to regulate the details of hygiene management. However, government evaluation reports have noted that schools lack kitchen 
Table 6 Proportion (\%) of Mid-Day Meal food allowances (Table 4) in comparison to the RDA for Indians (Table 5)

\begin{tabular}{|c|c|c|c|c|c|c|c|}
\hline \multicolumn{2}{|c|}{ Years } & $\begin{array}{c}\text { Energy } \\
(\%)\end{array}$ & $\begin{array}{l}\text { Protein } \\
(\%)\end{array}$ & $\begin{array}{c}\text { Food grains } \\
(\%)\end{array}$ & $\begin{array}{c}\text { Pulses } \\
(\%)\end{array}$ & $\begin{array}{c}\text { Vegetables } \\
(\%)\end{array}$ & $\begin{array}{c}\text { Oil \& fat } \\
(\%)\end{array}$ \\
\hline \multicolumn{2}{|c|}{$4 \sim 6$} & 33 & 60 & 83 & 67 & 20 & 20 \\
\hline \multicolumn{2}{|c|}{$7 \sim 9$} & 27 & 41 & 56 & 33 & 17 & 17 \\
\hline \multirow{2}{*}{ 10 12 } & Boy & 21 & 30 & 33 & 33 & 13 & 14 \\
\hline & Girl & 22 & 30 & 42 & 33 & 13 & 14 \\
\hline \multirow{2}{*}{$13 \sim 15$} & Boy & 25 & 37 & 36 & 40 & 17 & 17 \\
\hline & Girl & 30 & 39 & 45 & 50 & 19 & 19 \\
\hline
\end{tabular}

Based on Nutrient Requirements and Recommended Dietary Allowances for Indians $(2009)^{31)}$

infrastructure and utensils ${ }^{9,33)}$.

When it comes to dietary education, official sources mention the need for information, education, and communication connected with the MDM program ${ }^{13)}$. No report on dietary education has been issued. Instead, the public has been encouraged to wash hands before and after meals and after working in the kitchen garden.

\section{MDM evaluations, the PDCA, and outcomes}

1) Process evaluation

In India, a process evaluation of the MDM scheme is enforced, with the operational situation (e.g., lunch coverage) reported by each school to the state and by the state to central government. Central government reports on nutritional and hygiene management, but does not report on nutrition education.

This study has found that MDM process evaluations target coverage and the quality of school meals, including quality control, hygiene management, and children's dietary education. Both coverage and the working day ratio are high, although these figures include absent children and many children who do not attend school at all. The Indian central government has attempted to solve these problems by introducing "Aadhaar" (Individual Number System of India), a system imported into the MDM scheme to capture the actual number of children and achieve $100 \%$ coverage $\mathrm{e}^{35)}$.

In relation to the quality of school meals, the agreed nutritional standards do not supply one-third of the children's RDA. A full process evaluation could be carried out by recording the children's preferences and rates of leftover food and conducting satisfaction research regularly.

The official hygiene management guidelines are not adequate for preparing kitchen infrastructure, and many school kitchens do not comply with the guidelines. Hygiene management records should be reported to the state through ICT (Information and Communication Technology $)^{26)}$; in the present study, these data could not be gathered. If such data were available, a more detailed process evaluation could be carried out.

2) Outcome evaluation

Concepts of "hunger" and "education" were examined in relation to the MDM program goals. First, it is impossible to measure the program's effectiveness in alleviating hunger. We could not find national data on the physical and nutritional status of children (in Classes I-VIII) because some schools perform physical checkups and some do not. Others do checkups, but do not keep any $\operatorname{records}^{33)}$. It is therefore impossible to evaluate the extent to which children's nutritional status has improved nationally, following the introduction of the school meal program.

It is also difficult to assess the impact of the MDM program on education. UNESCO statistics show that gross and net enrollment ratios have been rising and stabilizing, with the number of out-of-school children falling conspicuously since $2002^{36)}$. According to teachers cited in the report, Performance Evaluation of Cooked Mid-day Meal $(2010)^{7)}$, the introduction of the MDM program is not the only cause of increased enrollment; other factors, including the results of Sarva Shiksa Abhiyan (SSA), may also have increased attendance. SSA is the Indian government's flagship program for achieving "universal elementary education;" it was launched in 2000. SSA was inspired by a surge of interest in public education and it introduced a scholarship system. These findings demonstrate that the MDM, in conjunction with other government initiatives to 
promote compulsory education, has led to increased enrollment rates. Finally, the report argues that the MDM program alone is not enough to keep children in public school because a growing section of society wants better quality education. As a result, the rates of enrolment in private schools have been rising, while the number of children targeted by the MDM program has been falling ${ }^{33)}$.

3) The extent to which the PDCA is enforced

SMCs must evaluate MDM programs regularly, at the national, state, district, and block levels. With using each SMC-held ratio, this study has examined the extent to which the PDCA is being enforced. An SMC must convene twice a year at the national and state levels, and once a month at the district and block levels. The report, Details of NSMC and SMC meetings during 2009 10 to 2013 14 ${ }^{33)}$, states that the average enforcement ratios for national, state, district, and block level SMCs were 60\%, 52\%, 21\%, and $17 \%$, respectively. At the national and state levels, the SMCs-held ratios were low, despite being calculated only twice a year. The block-level SMC-held ratio was the lowest, in spite of closing schools. In fact, the MDM PDCA system could not be implemented adequately.

\section{Discussion}

Initiating SSA and institutionalizing the MDM scheme has created the world's largest school meal program in India. The program includes high coverage, monitoring systems, and standards for food and hygiene. Developing countries seldom have such systems. India's MDM program can therefore serve as a reference for other countries initiating school meal programs. Previous Japanese experiments suggest that the next steps for the MDM program might include the following. A meal that satisfies hunger is not enough; children could receive their nutritional RDA if MDM food norms and standards were reviewed. To achieve higher levels, improving the quality of school meals would be preferable and the program should make the best possible use of the MDM scheme's Management and Monitoring Evaluation system. To evaluate outcomes, data on children's health checks should be recorded in all states and UTs. Since the central government introduced "Aadhaar" to achieve $100 \%$ coverage, this program could be used to manage data relating to chil- dren's health checks.

Finally, children need a dietary education in order to have a healthy future. When children grow up with food literacy, they can provide their own children with better nutrition. In Japan, every school has a dietitian who takes part in managing the school lunch program. His or her responsibilities include creating menus, hygiene management, and many related areas, including food education. If dieticians played an active role in the Indian school meal program, it would be easier to take the next steps.

This study has some limitations. Researchers consulted reports and articles published in English, without carrying out a field study. The analysis was conducted without a thorough understanding of the working practices of dieticians in India. In addition, the authors may have viewed the school meal standards negatively because they did not fully understand the decision-making process that created the norms and standards. In addition, schools had no hygiene-related records, making it impossible to analyze and evaluate the process; it was therefore necessary to rely only on governmental reports.

\section{Conclusions}

India's MDM program has been institutionalized, along with compulsory education. The levels of coverage and working days are high in the MDM program. However, school attendance rates are relatively low. The MDM standard meal did not provide one-third of the RDA; furthermore, $90 \%$ of the meal samples failed to satisfy the agreed standards. Although guidelines for hygiene management were published, they were difficult to observe because schools lacked well-equipped kitchens and utensils.

India's gross and net school enrollment ratios have been rising and stabilizing; with the introduction of the MDM, the number of out-of-school children has conspicuously fallen. However, it is difficult to evaluate the extent to which nourishment has improved, because there has not been a national investigation of the MDM program. The PDCA system has been in place, and SMCs have assumed a key role in implementing it.

The world's largest-scale school meal program has been realized, first, through the introduction of the nationwide MDM program, alongside compulsory education. The Japanese experience suggests that introducing a chil- 
dren's national health surveillance system would be useful in evaluating improvements in children's nutrition due to the MDM program.

\section{Acknowledgements}

The authors would like to express their deepest appreciation to Professor Nobuko Murayama. We would like to thank all of the members of this project.

\section{Conflict of Interest}

The authors confirm that they have no conflicts of interest.

\section{References}

1) World Food Program: State of school feeding worldwide 2013, pp. 1-124 (2013) WFP, Rome

2) Bundy, D., Burbano, C., Grosh, M., et al.: Rethinking school feeding: Social safety nets, child development, and the education sector (2009) The World Bank, Washington, D.C.

3) Aliyar, R., Gelli, A., Hamdani, S.H.: A review of nutritional guidelines and menu compositions for school feeding programs in 12 countries, Frontiers in Public Health, 3, 1-39 (2015)

4) Chutani, A.: School lunch program in India: background, objectives and components, Asia Pac. J. Clin. Nutr., 21, 151-154 (2012)

5) World Bank: World Bank Open Data. https://data. worldbank.org/indicator/SP.POP.TOTL?locations=IN\& view=chart, https://data.worldbank.org/indicator/SP. POP.0014.TO.ZS?locations=IN\&view=chart (Accessed February, 28, 2018)

6) International Institute for Populations Sciences: National Family Health Survey-4, 2015-2016, India Fact Sheet, pp. 2-3 (2016) International Institute for Populations Sciences, Mumbai

7) National Nutrition Monitoring Bureau: Diet and Nutritional Status of Rural Population, NNMB Technical Report No. 21, pp. 91-92 (2002) National Institute of Nutrition Indian Council of Medical Research, Hyderabad

8) Govt. of India Ministry of Human Resource Development (MHRD) Department of School Education \& Literacy: Working Group Report on Elementary Education and Literacy 12th Five Year Plan 2012-2017, pp. 170-237 (2011) Department of School Education and Literacy, Ministry of Human Resource Development, Government of India, New Delhi

9) Programme Evaluation Organisation Planning Commission Govt. of India: Performance Evaluation of COOKED MID-DAY MEAL, pp. 1-65 (2010) Programme Evaluation Organisation Planning Commission Government of India, New Delhi
10) Kusakabe, T.: Madrasa of Bangladesh, Islam Area Study Journal, 1, 23-36 (2009)

11) Ministry of Labour and Employment Child Labour Division: REVISED NCLP Guidelines, p. 4 (2016) Ministry of Labour and Employment Child Labour Division, New Delhi

12) Govt. of India MHRD Department of School Education \& Literacy: Guidelines of National Programme of Nutritional Support to Primary Education, Mid-Day Meal Scheme 2004, p. 2 (2004) MHRD, New Delhi

13) Govt. of India MHRD Department of School Education \& Literacy: Guidelines of National Programme of Nutritional Support to Primary Education, Mid-Day Meal Scheme 2006, p. 3 (2006) MHRD, New Delhi

14) Right To Food Campaign Secretariat: Supreme court orders on the right to food. http://www.righttofoodindia. org/data/scordersprimeratoolforaction.pdf (Accessed July, 30, 2017)

15) Govt. of India MHRD Department of School Education \& Literacy MDM Division: Extension of MDM programme to upper primary in educationally backward blocks. http://mdm.nic.in/Files/Guidelines/9.2007\%20revision. pdf (Accessed November, 25, 2017)

16) Govt. of India MHRD Department of School Education \& Literacy MDM Division: Extension of MDM Programme to eligible Madarsas/Maktabs supported under the SSA programme. http://mdm.nic.in/Files/Guidelines/8.temp\% 20003.pdf (Accessed November, 25, 2017)

17) Govt. of India MHRD Department of School Education \& Literacy MDM Division: Revision of food norm, cooking cost \& honourarium to cook-cum-helper under national programme for MDM in schools-regarding (31st December 2009). http://mdm.nic.in/Files/Guidelines/6.Rifision\% 20of\%20norns\%20MDM1_.pdf (Accessed November, 25, 2017)

18) Govt. of India MHRD Department of School Education \& Literacy MDM Division: Setting up of Sterring cum Monitoring Committee at the state, district and block level to oversee the implementation of Mid-Day Meal scheme. http://mdm.nic.in/Files/Guidelines/2.SSMC-mdm\%20 21.09.2010.pdf (Accessed November, 25, 2017)

19) Govt. of India MHRD Department of School Education \& Literacy MDM Division: Guidelines for engagement of voluntary organization/NGOs under Mid-Day scheme. http://mdm.nic.in/Files/Guidelines/3.MDM1\%2021.09. 2010.pdf (Accessed November, 25, 2017)

20) Govt. of India MHRD Department of School Education \& Literacy MDM Division: Providing Mid-Day Meal to children of National Child Labour Project (NCLP) schools as per norms fixed for upper primary children regarding. http://mdm.nic.in/Files/Guidelines/Guidlines-NCLP.pdf (Accessed November, 25, 2017)

21) Govt. of India MHRD Department of School Education \& Literacy MDM Division: Use of double fortified salt for MDMS (D.O.No.5-5/2011-MDM-1-1). http://mdm.nic.in/ Files/OrderCirculars/DFS_MDM.pdf (Accessed Novem- 
ber, 25, 2017)

22) Govt. of India MHRD Department of School Education \& Literacy MDM Division: Guidelines to ensure quality, safety and hygiene under the Mid-Day Meal scheme. http://mdm.nic.in/Files/OrderCirculars/MDM\%20 Guidelines\%20implementation\%20.pdf (Accessed November, 25, 2017)

23) Govt. of India MHRD Department of School Education \& Literacy MDM Division: Guidelines on food safety and hygiene for school level kitchens under Mid-Day Meal Scheme. http://mdm.nic.in/Files/Guidelines/2015/ Guidelines\%20_Food\%20Safety\%20and\%20Hygiene.pdf (Accessed November, 25, 2017)

24) Govt. of India MHRD Department of School Education \& Literacy MDM Division: MDM Rules-2015 with JS DO Letter. http://mdm.nic.in/Files/OrderCirculars/2015/ JS_DO_Letters_MDM_Rules.pdf (Accessed November, 25, 2017)

25) Govt. of India MHRD Department of School Education \& Literacy MDM Division: Model Memorandum of Understanding (MoU) for engagement of Civil Society Organization/Non Govt. Organisations (CSO/NGO) in MDM Scheme. http://mdm.nic.in/Files/Guidelines/2017/ Model_MOU_for_CSO_NGO-2017.pdf (Accessed November, 25, 2017)

26) Govt. of India MHRD Department of School Education \& Literacy: Mid- Day Meal Scheme. http://mdm.nic.in/ (Accessed July, 31, 2017)

27) Centre for Budget and Governance Accountability, India: Union Budget Analysis Tool 2017-18. http:// unionbudget2017.cbgaindia.org/\# (Accessed July, 31, 2017)

28) Govt. of India MHRD Bureau of Planning, Monitoring \& Statistics: Educational Statistics at a glance 2014, pp. 3-4 (2014) MHRD Bureau of Planning, Monitoring \& Statis- tics, New Delhi

29) Govt. of India MHRD Bureau of Planning, Monitoring \& Statistics: Statistics of School Education 2011-12, p. 69 (2014) Ministry of Human Resource Development Bureau of Planning, Monitoring \& Statistics, New Delhi

30) States and UTs in India: Brief note on MDM Sheme. http://mdm.nic.in/\# (Accessed July, 31, 2017)

31) National Institute of Nutrition: Nutrient Requirements and Recommended Dietary Allowances for Indians, A Report of the Expert Group of the Indian Council of Medical Research 2009. http://icmr.nic.in/final/rda-2010. pdf (Accessed July, 31, 2017)

32) National Institute of Nutrition Indian Council of Medical Research: Dietary Guidelines for Indians - A Manual, Second Edition (2011) National Institute of Nutrition Indian Council of Medical Research, Hyderabad

33) Comptroller and Auditor General of India: Performance Audit of Mid- Day Meal Scheme (2009-2010 to 2013-14), pp. 1-95 (2015) MHRD, New Delhi

34) Shukla, S.: Mid-Day Meal nutrition on paper, poor food on the plate, Economic \& Political WEEKLY, 49, 51-57 (2014)

35) Govt. of India MHRD Department of School Education \& Literacy MDM Division: Aadhaar enrollment of 100\% students under Mid-Day Meal scheme. http://mdm.nic.in/ Files/OrderCirculars/2017/aadhar_enrollment-Let_ dt_16-8-2017.pdf (Accessed July, 31, 2017)

36) United Nations Educational, Scientific and Cultural Organization, Institute for Statistics: Children out of school, primary (\%), School enrollment, primary (\% net) and (\% gross) in India. http://uis.unesco.org/ (Accessed July, 31, 2017)

(Received September 24, 2017; Accepted June 5, 2018) 